\title{
Desempenho, consumo e digestibilidade de cordeiros em confinamento recebendo silagens de capim elefante com diferentes proporções de casca desidratada de maracujá
}

\section{Performance, intake and digestibility of feedlot lambs receiving elephant grass silage with different proportions of dried peel of passion fruit}

\author{
Braulio Crisanto Carvalho da Cruz ${ }^{*}$; Cristiane Leal dos Santos-Cruz ${ }^{2}$; Aureliano \\ José Vieira Pires²; Jefferson Bomfim Rocha3; Suely Santos ${ }^{3}$; Milena \\ Patrícia Viana Bastos ${ }^{4}$
}

Resumo

\begin{abstract}
Avaliou-se o consumo, a digestibilidade, e o desempenho de silagens de capim-elefante, contendo diferentes níveis de inclusão $(0 ; 10 ; 20$ e 30\%) de casca de maracujá desidratada na matéria natural do capim-elefante, em um delineamento inteiramente casualizado, com 4 repetições. O capim elefante foi cortado com 60 dias de idade, picado e ensilado em tonéis juntamente com as proporções de casca de maracujá desidratada conforme cada tratamento. Após 30 dias de armazenagem os silos foram abertos para avaliações. Observou-se que a inclusão do resíduo influenciou o consumo e a digestibilidade de alguns nutrientes $(\mathrm{P}<0,05)$. Houve efeito para o ganho de peso médio diário e ganho total dos cordeiros, sendo que para cada $1 \%$ de casca de maracujá desidratada adicionada elevou-se 2,42\% o GMD. A conversão alimentar apresentou efeito linear decrescente $(8,9 ; 9,2 ; 8,6$ e 7,2), respectivamente, entre os tratamentos, permitindo concluir que, a casca de maracujá desidratada pode ser utilizada em até $30 \%$ de inclusão ao capim-elefante.
\end{abstract}

Palavras-chave: Consumo, ensilagem, Passiflora edulins

\begin{abstract}
The consumption, digestibility, and performance was evaluated of lambs fed silage elephant grass containing different inclusion levels of passion fruit peel dried $(0,10,20$ and 30\%) in natural matter of elephant grass, in a randomized completely randomized design with four replications. The elephant grass was cut at 60 days of age, chopped and ensiled in barrels along with the proportions of dried passion fruit peel, according to each treatment. After 30 days, the silos were opened for evaluation. It was observed that the inclusion of the residual affected the intake and digestibility of certain nutrients $(\mathrm{P}<0.05)$. Effect was observed for average daily weight gain and total gain of the lambs, and for every $1 \%$ of dried passion fruit peel added the ADG increased $2.42 \%$. The feed conversion showed decreasing linear effect (8.9, 9.2, 8.6 and 7.2), respectively, among treatments. It is concluded that the dried passion fruit peel can be added up to $30 \%$ of the elephant grass.
\end{abstract}

Key words: Consumption, ensilage, Passiflora edulins

1 Prof. do Instituto Médio Agrário de Waku Kungo- Angola, e Universidade Estadual do Sudoeste da Bahia, UESB. Waku kungo/ Kunaza Sul. E-mail: brauliocruz@bol.com.br

2 Prof. Titular da UESB, Dept ${ }^{\circ}$ de Tecnologia Rural e Animal, DTRA/UESB. Itapetinga, BA. E-mail: aureliano@pesquisador. cnpq.br

3 Doutorando do Programa de pós-graduação em Zootecnia, da UESB. Itapetinga, BA. E-mail:jeffersonzootec@hotmail.com; suyzootec@hotmail.com

4 Mestrando do Programa de pós-graduação em Zootecnia da UESB. Itapetinga, BA. E-mail: negamil@hotmail.com

* Autor para correspondência

Recebido para publicação $11 / 03 / 2010$ Aprovado em 20/09/201 1 


\section{Introdução}

A cadeia de produção da carne ovina desponta com grandes perspectivas tanto para o mercado interno, como para o mercado externo. No entanto, mesmo com o aumento do consumo nacional, ou seja, com a média aumentando de 0,46 kg-1 habitante-1 ano para 0,7 kg-1 habitante-1 ano (FAO, 2008), o mercado ainda se encontra muito aquém de países como a Austrália e Nova Zelândia, que apresentam consumo médio-1 habitante-1 ano-1 de $30 \mathrm{~kg}$ e $20 \mathrm{~kg}-1$ ano, respectivamente.

A casca de maracujá desidratada é um resíduo de agroindústria disponível no nordeste brasileiro, com valor energético (Lousada Júnior, 2006), que pode atender as exigências nutricionais de cordeiros em fase de crescimento, modificando o tipo de desenvolvimento e qualidade dos cortes a serem comercializados, garantindo regularidade na oferta da carne ovina.

O capim elefante (Pennisetum purpureum, Schum.) apresenta alto teor de umidade no momento ideal de corte, baixo teor de carboidratos solúveis e ainda elevada capacidade tampão, prejudicando assim, uma boa fermentação e conseqüentemente uma silagem de qualidade (COSTA et al., 2004). O uso de aditivos absorventes promove aumento no teor de matéria seca, garantindo melhores condições para as fermentações desejáveis (LOUSADA JÚNIOR et al., 2006).

Como possibilidade de utilização desses subprodutos, Neiva et al. (2006) sugeriram o uso na forma de aditivos na ensilagem de capim-elefante. Constam na literatura citações sobre o uso do subproduto do maracujá in natura, e relatos de que a adição desse subproduto melhorou a qualidade das silagens (REIS et al., 2000).

Vieira, Vasques e Silva (1999), analisando as cascas do fruto de maracujá roxo, observaram valores de 43,75; 35,06 e 8,56\% na MS para FDN, FDA e PB, respectivamente. Alves, Fontes e Ribeiro (2002) observaram que os subprodutos de abacaxi, maracujá e melão podem ser utilizados na alimentação animal, baseados nos consumos e coeficientes de digestibilidade da matéria seca que foram semelhantes aos de volumosos de boa qualidade como o milho e o sorgo.

Objetivou-se avaliaro consumoe a digestibilidade dos nutrientes, ganho de peso e conversão alimentar em cordeiros Santa Inês alimentados com silagens de capim elefante com diferentes proporções de casca de maracujá desidratada.

\section{Material e Métodos}

O experimento foi conduzido no centro de Ensaios Nutricionais de Ovinos e Caprinos - Enoc, da Universidade Estadual do Sudoeste da BahiaUesb, na cidade de Itapetinga-BA.

Foram avaliadas quatro diferentes silagens, constituídas de capim elefante (Pennisetum purpureum, Schum) e casca de maracujá desidratada (Passiflora edulins) - CMD, nas seguintes proporções e/ou tratamentos: T1: 100\% capimelefante; T2: 90\% capim-elefante $+10 \%$ CMD; T3: $80 \%$ capim-elefante $+20 \%$ CMD; T4: $70 \%$ capimelefante $+30 \% \mathrm{CMD}$, com base na matéria natural $(\mathrm{MN})$.

O resíduo de maracujá foi cedido pela empresa de processamento de sucos Necttare Indústria e Comercio de Produtos Alimentícios Ltda, situada no município de Feira de Santana-BA. A desidratação e secagem da casca de maracujá foi feita num pátio de cimento da própria empresa, expondo-a ao sol, a uma temperatura média de $37^{\circ} \mathrm{C}$, procedendose quatro reviras ao dia para homogeneização do material. À noite, a casca foi amontoada e coberta com uma lona plástica de cor preta, sendo espalhada novamente no dia seguinte. O processo foi finalizado quando a casca de maracujá atingiu um teor de $85 \%$ de MS, o que ocorreu em um período de seis dias.

O capim-elefante foi oriundo de uma capineira já estabelecida do campus da Uesb, em Itapetinga$\mathrm{Ba}$, cortado aos 60 dias de idade. 
Como silos experimentais, foram utilizados 32 tonéis de 200 litros, onde foi adicionada a quantidade de $100 \mathrm{~kg}$ de forragem, com uma densidade de 500 $\mathrm{kg} / \mathrm{m}^{3}$. O material foi pesado e homogeneizado de acordo com os tratamentos, sendo, posteriormente, compactado nos silos, com a utilização de "soquetes" de concreto e pisoteio humano. Após 30 dias da ensilagem, os silos foram abertos. No momento da ensilagem a composição química do capim elefante era de $24 \% \mathrm{MS}, 4,3 \% \mathrm{~PB}, 78 \%$ de FDN e $45 \%$ de FDA, a casca desidratada de maracujá apresentava $85 \%$ de MS, $13,4 \%$ PB, $59 \%$ FDN e $49 \%$ de FDA.

As amostras foram pré-secas em estufa de ar forçado, 55oC por $72 \mathrm{~h}$, posteriormente, moídas em moinho com peneira de $1 \mathrm{~mm}$ e armazenadas em recipientes de plástico. Na amostra pré-seca, foi determinado o teor de matéria seca (MS), conforme metodologia descritas por Van Soest, Mertens e Deinum (1978), assim como, o teor de fibra em detergente neutro (FDN), fibra em detergente ácido (FDA), celulose (CEL), hemicelulose (HEM), lignina (LIG), e matéria mineral (MM), proteína bruta (PB), extrato etéreo (EE), (Tabela1).

Para avaliação do ensaio de digestibilidade foram utilizados 16 cordeiros da raça Santa Inês, não castrados, com peso médio de $25 \mathrm{~kg}$, em delineamento inteiramente ao acaso, com quatro tratamentos e quatro repetições. Os animais foram pesados no início do experimento, vermifugados e distribuídos ao acaso em baias individuais de 1,0 x 1,5 m, com água ad libitum. O experimento teve duração total de 15 dias, sendo 10 dias de adaptação e 5 dias de período experimental (coleta total de fezes).

O concentrado utilizado na dieta composto por farelo de milho, farelo de soja e sal mineral foi formulado de acordo com o NRC (1985), para um ganho diário de $200 \mathrm{~g}$, em uma dieta isoprotéica, com $13 \%$ PB. A dieta foi fornecida diariamente às 7:00 e 16:00 horas, em uma quantidade calculada para permitir uma sobra de $10 \%$. Utilizou-se uma relação volumoso:concentrado de 60:40.

Tabela 1. Composição bromatológica das dietas.

\begin{tabular}{lcccc}
\hline Nutrientes & \multicolumn{4}{c}{ Níveis de adição de casca de maracujá desidratada (\%) } \\
\cline { 2 - 5 } & $\mathbf{0}$ & $\mathbf{1 0}$ & $\mathbf{2 0}$ & $\mathbf{3 0}$ \\
\hline Matéria seca & 23,2 & 28,9 & 33,1 & 41,8 \\
Proteína bruta & 5,4 & 8,5 & 10,2 & 11,9 \\
Extrato etéreo & 2,2 & 2,2 & 2,3 & 2,3 \\
Carboidratos totais & 83,2 & 79,8 & 78,0 & 77,2 \\
Fibra em detergente neutro & 76,5 & 68,5 & 63,7 & 58,9 \\
Fibra em detergente ácido & 58,4 & 58,4 & 50,2 & 46,8 \\
Lignina & 9,8 & 9,9 & 9,1 & 9,2 \\
\hline
\end{tabular}

As fezes eram coletadas às 6:00 e 15:30 horas, diariamente, por 5 dias, por meio de sacolas coletoras, obtendo um total de $100 \mathrm{~g}$ por animal e realizando uma amostragem composta no final do período experimental. As amostras foram pré- secadas em estufa de ar forçado a $55 \mathrm{oC}$ por $72 \mathrm{~h}$ e, posteriormente, moídas em moinho tipo Willey com peneira de crivo $1 \mathrm{~mm}$ e armazenadas em recipientes de plástico. Determinou-se, a partir daí, os teores de MS; PB; FDN; FDA; HEMI; EE e MM CHOT 
e carboidratos não fibrosos (CNF) foram calculados segundo equações sugeridas por Sniffen, O Connor e Van Soest (1992). O teor de nutrientes digestíveis totais (NDT) foi calculado de acordo com o sistema desenvolvido pela Universidade de Cornell (SNIFFEN; O`CONNOR; VAN SOEST, 1992).

O desempenho teve a duração de 52 dias e foram utilizados os mesmos cordeiros e tratamentos correspondentes, sendo pesados no início e final do experimento, vermifugados e alojados em baias individuais de 1,0 x 1,5 m, com água ad libitum. A dieta foi fornecida, garantindo sobras diárias de aproximadamente 10\%, às 7:00 e 16:00 horas. Foram avaliados o ganho médio de peso diário (GMPD), ganho de peso total (GP) e a conversão alimentar (CA) no período total de confinamento.

Os dados foram submetidos à análise de variância
(PROC ANOVA) e de regressão (PROC REG), quando significativos, com auxilio com auxilio do software SAS (SAS, 2001). A escolha das equações baseou-se na significância dos coeficientes linear e quadrático, por meio da análise de probabilidade de "t", com 5\% de probabilidade, e o $\mathrm{R}^{2}$ escolhido foi o que ofereceu melhor ajuste dos dados.

\section{Resultado e Discussão}

As médias de consumos de matéria seca total, de proteína bruta, de fibra em detergente neutro e fibra em detergente ácido, em percentual do peso vivo, não foram diferentes $(\mathrm{P}>005)$ quando os cordeiros foram alimentados com as silagens de capimelefante com níveis crescentes de adição de casca de maracujá desidratada (Tabela 2).

Tabela 2. Consumo de matéria seca Total (CMS), proteína bruta (CPB), fibra em detergente neutro (CFDN) e fibra em detergente ácido (CFDA), (g/animal/dia e \%PV), das silagens de capim elefante com níveis crescentes de adição de casca de maracujá desidratada (CMD).

\begin{tabular}{|c|c|c|c|c|c|c|c|}
\hline \multirow[t]{2}{*}{ variáveis } & \multicolumn{4}{|c|}{ Níveis de adição de CMD (\%) } & \multirow{2}{*}{$\begin{array}{l}\text { Equação de } \\
\text { Regressão }\end{array}$} & \multirow[t]{2}{*}{$\mathbf{R}^{2}$} & \multirow{2}{*}{$\begin{array}{l}\text { CV } \\
(\%)\end{array}$} \\
\hline & $\mathbf{0}$ & 10 & 20 & 30 & & & \\
\hline$\overline{\mathrm{CMS} \text { (g/dia) }}$ & 842,1 & 964,8 & 1204,1 & 1200,5 & $\bar{Y}=824,13+22,61 x-0,32 x^{2}$ & 93 & 16,5 \\
\hline CMS (\%PV) & 3,4 & 4,0 & 4,7 & 4,7 & $\dot{Y}=4,2$ & - & 11,8 \\
\hline CPB (g/dia) & 135,5 & 161,1 & 212,2 & 196,9 & $Y=130,91+5,42 x+0,10 x^{2}$ & 88 & 13,7 \\
\hline CPB (\%PV) & 0,57 & 0,67 & 0,80 & 0,77 & $\dot{Y}=0,70$ & - & 13,1 \\
\hline CFDN (g/dia) & 519,6 & 498,9 & 660,8 & 604,4 & $\dot{Y}=508,5+4,16 x$ & 50 & 19,4 \\
\hline CFDN (\%PV) & 1,9 & 2,0 & 2,5 & 2,5 & $\dot{Y}=2,2$ & - & 10,6 \\
\hline CFDA (g/dia) & 376,7 & 335,2 & 420,6 & 395,0 & $\dot{Y}=381,8$ & - & 15,4 \\
\hline CFDA (\%PV) & 1,4 & 1,4 & 1,6 & 1,5 & $\dot{Y}=1,5$ & - & 13,0 \\
\hline
\end{tabular}

$\mathrm{R}^{2}$ : coeficiente de determinação.CV: coeficiente de variação.

Considerando, o consumo de mataria seca em g/ dia, foi verificado efeito quadrático $(\mathrm{P}<0,05)$, com 842,$1 ; 964,8 ; 1204,1$ e 1200,5, respectivamente, para os níveis $(0,10,20$ e 30\%) de adição da casca de maracujá desidratada, o que, provavelmente, tenha ocorrido pela influência dos elevados teores de matéria seca das silagens contendo casca de maracujá, permitindo um maior consumo, já que, volumosos com baixos teores de matéria seca podem limitar o consumo. Resultado similar a esse, 
foi encontrado por Lousada Júnior et al. (2005), estudando a casca de maracujá desidratada como única fonte de alimentação para ovinos, observando um consumo de 1200 g e 3,5\% para CMS g/dia e CMS \%PV, respectivamente. Neiva et al. (2006), trabalhando com níveis de casca de maracujá desidratada de $0 ; 3,5 ; 7,0 ; 10,5$ e $14 \%$, em adição ao capim elefante, observaram que para cada $1 \%$ de casca de maracujá adicionada, elevou-se 19,4\% o consumo de matéria seca.

Reis et al. (2000), avaliando silagens de capimelefante, observaram aumento no consumo de matéria seca expresso em g/UTM até o nível de $48 \%$ de adição de casca de maracujá in natura, porém, a partir desse percentual, o consumo foi reduzido, pois o baixo teor de matéria seca da casa de maracujá in natura atuou como fator limitante.

A casca de maracujá desidratada apresentou baixo teor de FDN (59,0\%), valor inferior ao capimelefante $(78,6 \%)$, havendo efeito significativo para o consumo de matéria seca em g/dia para as proporções de 20 e $30 \%$ de casca de maracujá desidratada. Este aumento foi explicado por Van Soest (1965), inferindo que o consumo de MS é limitado por teores de FDN superiores a $60 \%$.

Os consumos de proteína bruta, expressos em g/dia, variaram de 161,1; 212,2 a 196,9, respectivamente, com adição de 10,20 e 30\% de casca de maracujá desidratada, sem que houvesse diferença quando este consumo foi expresso em percentual do peso vivo, apresentando média 0,70. Esse valor foi superior ao encontrado por Lousada Júnior et al. (2005), de 0,43. Neiva et al. (2006) relataram que a cada $1 \%$ de inclusão de casca de maracujá desidratada, o consumo de proteína bruta aumentou em 2,8 g, justificado pelo maior teor e consumo de matéria seca e pelos elevados teores de PB.

Com a inclusão de $10 \%$ de casca de maracujá desidratada, provavelmente, ocorreu o bom funcionamento ruminal, pois o nível mínimo de $6,25 \%$ de proteína bruta foi atingido, o que é recomendado por Silva e Leão (1979). Os níveis de 20 e $30 \%$ de casca de maracujá desidratada supriram as exigências nutricionais dos ovinos, pois segundo o NRC (1985), o consumo de PB necessário, para que ovinos de 20 a $30 \mathrm{~kg}$ atinjam ganho de peso de $250 \mathrm{~g} / \mathrm{dia}$, é de $168 \mathrm{~g} / \mathrm{dia}$. Santos (1995), trabalhando com resíduo de maracujá in natura (90\%), mais bagaço de cana (10\%) na alimentação de ovinos, observou consumos de proteína bruta de $6,5 \mathrm{~g} / \mathrm{UTM}$.

A adição de casca de maracujá desidratada ao capim elefante alterou o consumo de FDN em g/dia, havendo aumento de $4,16 \%$ para cada $1 \%$ de casca de maracujá. Neiva et al. (2006) não encontraram diferença $(\mathrm{P}>0,05)$ para FDN e FDA, observando médias de consumo em \% PV, inferiores 1,7 e 1,2\% para FDN e FDA. Lousada Júnior et al. (2005) encontrou valores superiores para os consumos de FDN $(706,5)$ e FDA $(591,3)$ em g/dia, mas apresentou valores similares, ao deste trabalho, quando os consumos foram expressos em percentual do peso vivo, sendo 2,0 e 1,7, respectivamente.

$\mathrm{O}$ acréscimo no consumo de FDN em g/dia, possivelmente, pode ser explicado considerando a composição bromatológica das dietas (Tabela 1), pois houve redução nos valores de FDN (de 76,5 para 58,9) e FDA (de 58,4 para 46,8), com a inclusão de 20 e $30 \%$ de casca de maracujá desidratada. Ferreira et al. (2002) mediram o consumo voluntário de silagens de capim elefante com subprodutos da indústria de suco de caju (34,5\% FDA) em níveis de $0,12,24$ e $36 \%$ de inclusão do caju em dietas para ovinos, e observaram consumo de FDA de 128,2 a 205,5 g/animal/dia.

A inclusão de casca de maracujá desidratada em até $30 \%$, aumentou o consumo, em g/dia, de matéria seca, de proteína bruta e fibra em detergente neutro. Sugere-se que sejam realizadas pesquisas com adição de níveis superiores a 30\%.

Os coeficientes de digestibilidade aparente da matéria seca das silagens avaliadas, não foram diferentes $(\mathrm{P}>0,05)$ (Tabela 3$)$, apresentando valor 
médio de $71,2 \%$, acima de 50\%, índice mínimo satisfatório para que não haja prejuízos para o desempenho animal, conforme Milford e Minson (1966). Reis et al. (2000) trabalhando com casca de maracujá fresco em substituição ao capim elefante, em dietas para carneiros com idade indefinida, encontraram efeito positivo na digestibilidade da matéria seca, encontrando valores de 69,$2 ; 87,3$; 79,3 e 69,1, para os tratamentos com 100, 75, 50, 25 e $0 \%$ de casca de maracujá, respectivamente.

Tabela 3. Coeficientes de digestibilidade aparente da matéria seca (CDMS), proteína bruta

(CDPB), fibra em detergente neutro (CDFDN), fibra em detergente ácido (CDFDA), ganho de peso total (GP), ganho médio diário (GMD) e conversão alimentar (CA), de silagens de capim elefante com níveis crescentes de adição de casca de maracujá desidratada (CMD).

\begin{tabular}{|c|c|c|c|c|c|c|c|}
\hline \multirow[t]{2}{*}{ Nutrientes } & \multicolumn{4}{|c|}{ Níveis de adição de CMD (\%) } & \multirow{2}{*}{$\begin{array}{l}\text { Equação de } \\
\text { Regressão }\end{array}$} & \multirow[t]{2}{*}{$\mathbf{R}^{2}$} & \multirow{2}{*}{$\begin{array}{l}\text { CV } \\
(\%)\end{array}$} \\
\hline & $\mathbf{0}$ & 10 & 20 & 30 & & & \\
\hline$\overline{\mathrm{CDMS}}$ & 68,8 & 72,4 & 72,6 & 71,3 & $\hat{Y}=71,2$ & - & 3,4 \\
\hline CDPB & 86,3 & 85,0 & 83,3 & 78,8 & $\dot{Y}=86,98-0,24 x$ & 91,14 & 2,0 \\
\hline CDFDN & 62,0 & 58,6 & 65,2 & 66,6 & $\dot{Y}=63,1$ & - & 12,1 \\
\hline CDFDA & 61,9 & 58,6 & 65,2 & 66,6 & $\dot{Y}=63,0$ & - & 12,1 \\
\hline NDT & 67,5 & 70,1 & 71,0 & 68,7 & $\dot{Y}=69,3$ & - & 13,0 \\
\hline GMD & 112,0 & 115,2 & 129,6 & 187,9 & $\dot{Y}=100+0,141 x$ & 85,9 & 22,1 \\
\hline GP kg & 6,0 & 6,2 & 7,0 & 10,1 & $\dot{Y}=5,36+0,131 x$ & 79,25 & 22,3 \\
\hline $\mathrm{CA}$ & 8,9 & 9,2 & 8,6 & 7,2 & $\dot{Y}=9,37-0,05 x$ & 69,30 & 25,2 \\
\hline
\end{tabular}

$\mathrm{R}^{2}$ : coeficiente de determinação.CV: coeficiente de variação.

Lousada Júnior et al. (2005) obtiveram 59,9\% de digestibilidade da matéria seca para a casca de maracujá, e Reis et al. (2000) encontraram $48,25 \%$ para silagens de capim-elefante. Neiva et al. (2006) avaliaram cordeiros e testaram 0,$0 ; 3,5$; 7,$0 ; 10,5$ e $14,0 \%$ de casca de maracujá desidratada em relação a matéria natural do capim elefante, e observaram que a adição provocou elevação nos valores da digestibilidade aparente da matéria seca das silagens.

A digestibilidade da proteína bruta apresentou efeito decrescente $(\mathrm{P}<0,05)$, com 86,$3 ; 85,0 ; 83,3$ e 78,8\%, para $0,10,20$ e $30 \%$ de inclusão de casca de maracujá, respectivamente. Ou seja, para cada $1 \%$ de inclusão, obteve-se elevação de 2,4 pontos percentuais nos valores da digestibilidade aparente da proteína bruta. Esses valores foram superiores aos de Neiva et al. (2006) que encontraram valores de 18,$3 ; 26,1 ; 34,3 ; 42,7$ e 51,3 para $0 ; 3,5 ; 7,0 ; 10,5$ e $14 \%$ de casca de maracujá desidratada. Reis et al. (2000) observaram que a digestibilidade da proteína bruta variou de $75 \%$ para com $100 \%$ capim-elefante à 87,3 para $100 \%$ de casca de maracujá in natura, com um aumento de $0,16 \%$ na digestibilidade para cada $1 \%$ de casca de maracujá.

Os coeficientes de fibra em detergente neutro e fibra em detergente ácido não apresentaram efeito $(\mathrm{P}>0,05)$ com a inclusão de casca de maracujá. Resultado similar foi encontrado por Neiva et al. (2006), com valores médios de 47,2 e 41,2, para o coeficiente de digestibilidade da FDN e FDA, respectivamente. Por outro lado, Reis et al. (2000) observaram elevações lineares nas digestibilidade de FDN, de 64,3 a 79,3, de silagens de capim 
elefante à medida que adicionaram subproduto de maracujá in natura em $100 \%$ de capim elefante e em $100 \%$ de casca de maracujá fresca, respectivamente. Para Lousada Júnior et al. (2005), os coeficientes de digestibilidade de FDN e FDA da casca de maracujá desidratadada foram de 56,2 e 65,4\%, respectivamente.

Os diferentes efeitos nos coeficientes de digestibilidade (Tabela 3) podem ser explicados pelo nível de alimentação, a capacidade ruminal e a caracterização bromatológica das dietas, que podem causar variações no tempo de retenção e, conseqüentemente, na digestibilidade. Essa afirmação foi realizada por Forbes (1995), assim como a de que, a digestibilidade é produto do tempo de retenção ruminal e das características de degradação dos alimentos em estudo.

Os nutrientes digestíveis totais apresentaram valor médio de 69,3\% (Tabela 3), superior ao encontrado por Lousada Júnior et al. (2005), de 52,9. Neiva et al. (2006) verificaram efeito linear $(\mathrm{P}<0,01)$ dos níveis de adição de casca de maracujá desidratada sobre os valores de NDT das silagens, em que, para cada $1 \%$ de inclusão de casca de maracujá às silagens de capim-elefante, os valores de NDT elevaram em $0,87 \%$.

Conforme já descrito na metodologia, os cordeiros apresentaram peso vivo médio inicial de $25 \mathrm{~kg}$. Todavia considerando a distribuição por tratamento, com $0,10,20$ e $30 \%$ de casca de maracujá desidratada, o peso vivo médio inicial foi de 24,$7 ; 24,5 ; 25,8$ e $25,5 \mathrm{~kg}$ e 30,$7 ; 30,7 ; 32,8$ e $35,7 \mathrm{~kg}$ de peso vivo médio final, respectivamente.

$\mathrm{O}$ ganho de peso e ganho médio diário aumentou de forma linear $(\mathrm{P}<0,05)$ (Tabela 3$)$, em que o GMD determinado foi de 112,0;115,2; 129,6 e 187,9 para os tratamentos com $0,10,20$ e $30 \%$ de casca de maracujá desidratada. Provavelmente, houve uma melhoria na composição do ganho dos ovinos devido à boa composição da dieta que continha silagem de capim elefante com $30 \%$ de casca de maracujá desidratada. Esses valores de ganho de peso estão abaixo dos reportados por outros autores. Moreno et al. (2010) alimentando cordeiros com silagem de milho encontraram um valor para ganho médio diário de 294 g, relatando valores próximos a estes como adequado para ovinos destinados à produção de carne. Furusho, Pérez e Lima (1997), em estudo com cordeiros Santa Inês em confinamento, recebendo pedúnculo de caju, encontraram um ganho de peso médio diário de $240 \mathrm{~g} / \mathrm{animal} / \mathrm{dia}$, acima da média verificada neste trabalho.

Borges, Azevedo e Sales (2004), em pesquisa com ovelhas alimentadas com dietas formuladas com diferentes níveis de polpa seca de caju (PSC), obtiveram ganhos de peso diário de 120,24 a $152,68 \mathrm{~g} / \mathrm{dia}$, valores próximos ao encontrado quando foi adicionado 20 e $30 \%$ de casca de maracujá desidratada. Andrade, Azevedo e Sales (2001) obtiveram resultados de ganho de peso baixos, com valores de 91,7 a 127,6 g/animal/dia, ao trabalharem com cordeiros sem raça definida, recebendo resíduos agro-industriais de acerola, melão e abacaxi no nível de $30 \%$ da ração total, em substituição ao capim elefante.

A conversão alimentar apresentou diferença $(\mathrm{P}<0,05)$ com adição de casca de maracujá desidratada (Tabela 3), decrescendo de forma linear, com a variação de 8,9 a 7,2. Ou seja, para cada $1 \%$ de casca de maracujá desidratada, a conversão alimentar foi reduzida em $0,05 \%$. Esse decréscimo explica o aumento do ganho de peso médio diário quando se adicionou casca de maracujá à dieta. Borges, Azevedo e Sales (2004) testaram diferentes níveis de pseudofruto de cajueiro em ovinos e encontraram resultados similares $(6,49$ a 9,83) aos obtidos neste estudo. Melhor conversão alimentar foi obtida por Furusho, Pérez e Lima (1997), sendo de 4,35, em cordeiros Santa Inês, recebendo dietas contendo pedúnculo de caju.

A adição de casca de maracujá desidratada ao capim elefante na ensilagem provoca diferença no coeficiente de digestibilidade da matéria seca, fibra em detergente neutro e fibra em detergente ácido, 
melhorando o desempenho de ovinos da raça Santa Inês. Recomenda-se adicionar casca de maracujá desidratada em até $30 \%$, na matéria natural, do capim elefante.

\section{Referências}

ALVES, G. R.; FONTES, C. A. A.; RIBEIRO, E. G. Influência do nível de matéria seca, e de uréia sobre a qualidade de silagens contendo polpa de abacaxi, em mistura com bagaço de cana ou feno de Coast cross. In: REUNIÃO ANUAL DA SOCIEDADE BRASILEIRA DE ZOOTECNIA, 39., 2002, Recife. Anais... Recife: Sociedade Brasileira de Zootecnia, 2002. CD-ROM.

ANDRADE, F. A. O.; AZEVEDO, A. R.; SALES, R. O. Consumo de nutrientes por ovinos alimentados com diferentes dietas à base de resíduos da agroindústria. Revista Científica de Produção Animal, Piauí, v. 3, n. 1, p. 68-76, 2001.

BORGES, P. H. R.; AZEVEDO, A. R.; SALES, R. O. Desempenho de ovinos alimentados com diferentes níveis de pseudofruto seco do cajueiro. Revista Científica de Produção Animal, Piauí, v. 3, n. 2, p. 24-34, 2004.

COSTA, N. de L.; TOWNSEND, C. R.; MAGALHÃES, J. A.; PEREIRA, R. G. de A. Curva de crescimento e composição química de Paspalum atratum Bras-009610 em Rondônia. In: ZOOTEC, 2., 2004, Brasília. Anais... Brasília: ABZ/ZOO, 2004. p. 1-4. CD-ROM.

FERREIRA, A. C. H.; NEIVA, J. N. M.; RODRIGUEZ, N. M.; PIMENTEL, J. C. M.; LOBO, R. N. B. Consumo voluntário das silagens de capim-elefante com diferentes níveis de subprodutos da indústria do suco de caju. In: REUNIÃO ANUAL DA SOCIEDADE BRASILEIRA DE ZOOTECNIA, 39., 2002, Recife. Anais... Recife: Sociedade Brasileira de Zootecnia, 2002. 1 CD-ROM.

FORBES, J. M. Physical limitation of feed intake in ruminants and its interaction with other factors affecting intake. In: ENGELHARDT, W. W.; LEONHARDMAREK, S.; BREVES, G. et al. (Ed.). Ruminant physiology: digestion, metabolism, growth and reproduction. Stuttgart: Enke, 1995. p. 217-232.

FURUSHO, I. F.; PÉREZ, J. R. O.; LIMA, G. F. C. Desempenho de cordeiros Santa Inês, terminados em confinamento, com dieta contendo pedúnculo do caju. In: REUNIÃO ANUAL DA SOCIEDADE BRASILEIRA DE ZOOTECNIA, 34., 1997, Juiz de Fora. Anais... Juiz de Fora: Sociedade Brasileira de Zootecnia, 1997. p. 38587.

LOUSADA JÚNIOR, J. E.; COSTA, J. M. C.; NEIVA,
J. N. M.; RODRIGUEZ, N. M. Caracterização físicoquímica de subprodutos obtidos do processamento de frutas tropicais visando seu aproveitamento na alimentação animal. Revista Ciência Agronômica, Fortaleza, v. 37, n. 1, p. 70-76, 2006.

LOUSADA JÚNIOR, J. E.; NEIVA, J. N. M.; RODRIGUES, N. M.; PIMENTEL, C. M. Consumo e Digestibilidade de Subprodutos do Processamento de Frutas em Ovinos. Revista Brasileira de Zootecnia, Viçosa, MG, v. 34, n. 2, p. 659-669, 2005.

MILFORD, R.; MINSON, D. J. Intake of tropical posture species. In: CONGRESSO INTERNACIONAL DE PASTAGENS, 9., 1965, São Paulo. Anais... São Paulo: Alarico, 1966. p. 815-822.

MORENO, G. M. B.; SOBRINHO, A. G. S.; LEÃO, A. G.; LOUREIRO, C. M. B.; PEREZ, H. L. Desempenho, digestibilidade e balanço de nitrogênio em cordeiros alimentados com silagem de milho ou cana-de-açúcar e dois níveis de concentrado. Revista Brasileira de Zootecnia, Viçosa, MG, v. 39, n. 4, p. 853-860, 2010.

NATIONAL RESEARCH COUNCIL - NRC. Nutrient requirement of sheeps. 6. ed. Washington: National Academy Press, 1985. 99 p.

NEIVA, J. N. M.; NUNES, F. C. S.; CANDIDO, M. J. D.; RODRIGUES, N. M.; LOBOS, R. N. B. Valor nutritivo de silagens de capim-elefante enriquecidas com subproduto do processamento do maracujá. Revista Brasileira de Zootecnia, Viçosa, MG, v. 35, n. 4, p. 1845-1851, 2006.

REIS, J.; PAIVA, P. C. A.; TIESENHAUSEN, I. M. E. V.; REZENDE, C. A. P. Composição química, consumo voluntário e digestibilidade de silagens de resíduos de fruto de maracujá (passiflora edulis Sims f. flavicarpa) e de capim-elefante Cv. Camerron e sua combinações. Ciência e Agrotecnologia, Lavras, v. 24, n. 1, p. 213-224, 2000.

SANTOS, L. E. Pastagens para ovinos. In: SIMPÓSIO PAULISTA DE OVINOCULTURA, 4., 1995, Campinas. Anais... Campinas: CATI, 1995. p. 1-18.

SAS Institute. Statistical analyses system: release 8.2. for Windows. Cary: SAS Institute, 2001.

SILVA, J. F. C.; LEÃO, M. I. Fundamentos de nutrição dos ruminantes. Piracicaba: Ed Livroceres, 1979. 380 p.

SNIFFEN, C. J.; O'CONNOR, J. D.; VAN SOEST, P. J. A net carboidrate and protein system for evaluating cattle diets. II. Carboidrate and protein availability. Journal of Animal Science, Madison, v.70, n. 11, p. 3562-3577, 1992.

VAN SOEST, P. J. Voluntary intake in relation to chemical composition and digestibility. Journal of Animal Science, 
Madison, v. 24, n. 3, p. 834-843, 1965.

VAN SOEST, P. J.; MERTENS, D. R.; DEINUM, B. Preharvest factors influencing quality of conserved forage. Journal of Animal Science, Madison, v. 47, n. 3, p. 712-20, 1978.

VIEIRA, C. V.; VASQUES, H. M.; SILVA, J. F. C. da.Composiçãoquímico-bromatológica e degradabilidade "in situ" da matéria seca, proteína bruta e fibra detergente neutro da casca do fruto de três variedades de maracujá (Passiflora spp). Revista Brasileira de Zootecnia, Viçosa, MG, v. 28, n. 5, p. 1148-1158, 1999. 
Cruz, B. C. C. et. al. 